\title{
O papel do fisiologista desportivo no futebol - Para quê \& por quê?
}

\author{
Paulo Roberto Santos Silva ${ }^{1}$
}

\section{RESUMO}

A fisiologia desportiva ainda é considerada uma especialidade relativamente nova no futebol. A figura do fisiologista desportivo e, conseqüentemente, sua função e formação, é desconhecida pela grande maioria daqueles que estão envolvidos nesta modalidade, não sabendo caracterizar o papel desse profissional numa equipe de futebol. É importante ressaltar que o especialista desta área trabalha diretamente junto ao fisicultor, cabendo a ele funções como: 1) trabalho em equipe passando informações constantes à comissão técnica sobre as condições funcionais dos jogadores; 2) avaliação sistemática dos atletas; 3) acompanhamento longitudinal das adaptações funcionais em decorrência do treinamento dos atletas e 4) capacidade de investigação e reflexão sobre diversos aspectos do futebol. Sendo assim, o fisiologista desportivo requer amplo conhecimento de metodologias científicas de avaliação funcional e treinamento desportivo, bem como o domínio específico de conceitos bioenergéticos direcionados para o futebol. Isso permite identificar o tipo de esforço e selecionar métodos adequados para o desenvolvimento do programa de treinamento do futebolista.

Concluindo, o fisiologista desportivo, em sua essência, é sobretudo um profissional de saúde que tem cada vez mais uma função educativa. Ele contribui para melhorar a informação científica que toda a comunidade esportiva deve ter sobre diversos aspectos de saúde do corpo humano e, em particular, quando submetido à realização de exercícios.

Palavras-chave: Fisiologista desportivo. Futebol. Medicina esportiva.

\footnotetext{
1. Fisiologista Desportivo.
}

Endereço para correspondência:

Paulo Roberto Santos Silva

Rua Frederico Bartholdi, 566 - Saúde

04193-000 - São Paulo, SP

Fone: (11) 6331-64 81 (Residência), 9998-2591 (Celular)

\section{ABSTRACT}

The role of the sports physiologist in soccer (football) what for and why?

Sports physiology is still considered a relatively new specialty in soccer. Small wonder, thus, that a sports physiologist, with his function and formation, is a personage unknown to most people engaged in this sport, for they are unable to characterize his role as a specialized professional in a soccer team. So it is important to lay stress on the fact that the work of such specialist in this area is directly connected with the trainer, as he performs, among others, duties like: 1) team work, conveying constant information about the players' functional condition to the technical commission; 2) systematic evaluation of the athletes; 3 ) longitudinal follow-up to the functional adaptation resulting from the training to which athletes are submitted; 4) investigation and reflection capacity regarding several aspects of the soccer (football) game. Consequently, it is logical to infer that a sports physiologist requires ample knowledge of the scientific methodologies about functional evaluation and sport training, apart from specific mastery of bioenergetic concepts aimed at the soccer (football) game, so as to allow to identify the kind of effort and, starting from there, adequate methods for the development of the soccer (football) players' training program.

In conclusion, the sports physiologist is essentially a professional concerned with health, whose function is more and more educational and intended to contribute to the improvement of the scientific information that every community must possess about several health aspects of the human body and, particularly, about the performance of exercises.

Key words: Sports physiologist. Soccer (football). Sports medicine.

\section{INTRODUÇÃO}

A medicina esportiva no Brasil em certos aspectos de organização, recursos humanos e materiais ainda está em fase de crescimento. 
A evolução, conscientização e o desenvolvimento do desporto em nosso país, como qualquer outro fator sociocultural, passa necessariamente por um processo de transformação, ainda que lentamente. A figura de especialistas compondo o staff em equipes esportivas, que podem dar ao esporte sua contribuição dentro de uma organização multidisciplinar, tem se constituído numa novidade ${ }^{1-2}$.

É importante ressaltar que a fisiologia do exercício direcionada para o esporte é apenas uma disciplina do curso de medicina desportiva. O pretendente ao exercício desta função necessita ter sólidos conhecimentos em fisiologia do exercício, organização e prescrição de treinamento, domínio de particularidades próprias no âmbito da modalidade esportiva e o conhecimento de metodologias científicas de avaliação em laboratório e campo.

No Brasil, assim como em muitos países desenvolvidos, mas de uma forma mais lenta, se começa a dar importância ao fisiologista desportivo no futebol.

Nos últimos anos o treinamento para jogadores de futebol de alto nível vem sofrendo modificação substancial em relação ao que era feito algumas décadas atrás. O número de jogos e de horas dedicadas às sessões de treinamentos aumentou significativamente. Desde então a dinâmica das cargas de treinamento também foi alterada, em decorrência da entrada de novos conceitos para a prática do futebol na atualidade.

Atualmente os clubes mais estruturados possuem seus laboratórios de fisiologia do exercício para dar ao setor de preparação física um maior suporte na realização de exercícios, com embasamento e controle científico.

O papel do fisiologista desportivo junto ao fisicultor na análise do programa de treinamento do atleta é de grande importância, pois relaciona-se com a dinâmica das cargas de trabalho durante a temporada futebolística. As proporções entre volume (quantidade) e intensidade (qualidade) dos exercícios realizados nos períodos chamados de preparatório e competitivo devem ser focalizadas diferente sob o ponto de vista da organização do treinamento.

A avaliação prévia do nível de aptidão física dos atletas, obtida por meio de testes fisiológicos, fornece condições objetivas ao fisicultor para realizar o treinamento em função das necessidades de cada atleta. De acordo com os resultados apresentados pelos jogadores é possível encurtar o tempo destinado à preparação geral em troca do trabalho específico, concentrando-se mais no trabalho com bola.

Os testes fisiológicos possibilitam verificar com precisão que qualidade física precisa ser desenvolvida em relação às necessidades da modalidade praticada. Sendo assim, uma análise minuciosa da atividade desportiva permitirá identificar o tipo de esforço dominante e a seleção de métodos adequados para o desenvolvimento do programa de treinamento.

$\mathrm{O}$ presente artigo pretende atingir os seguintes objetivos: 1) Caracterizar a presença e intervenção do fisiologista desportivo em equipes de futebol e 2) Justificar junto aos dirigentes dessa modalidade esportiva a necessidade deste profissional como parte integrante de uma comissão técnica.

\section{Nível de intervenção geral do fisiologista desportivo no futebol}

O fisiologista desportivo, em sua essência, é sobretudo um profissional de saúde que tem cada vez mais uma função educativa. Ele contribui para melhorar a informação científica que toda a comunidade esportiva deve ter sobre diversos aspectos funcionais do corpo humano e em particular quando submetido à realização de exercícios.

\section{Considerações sobre a intervenção específica do fisio- logista desportivo no futebol}

Durante uma partida de futebol ocorre uma grande variabilidade da demanda fisiológica e metabólica sobre os jogadores. A maior dificuldade que encontramos em cercar as necessidades do futebolista é o fato de que o futebol não é uma atividade de código predeterminado, ou seja, as solicitações motoras são imprevisíveis e muitas vezes o atleta se depara com situações para as quais nem sempre está preparado.

O maior desafio é conseguir individualizar as necessidades específicas de cada jogador de acordo com as características que são impostas pelo futebol, pois a atividade do futebolista é muito dinâmica e as variações e nuances de cada partida são imprevisíveis.

A compreensão básica dos sistemas energéticos utilizados no futebol é fundamental para o desenvolvimento adequado de programas de treinamentos nos períodos de preparação geral e específica, como também nos requerimentos individuais de cada posição.

$\mathrm{O}$ futebol moderno requer muitas qualidades físicas que parecem ser independentes da posição do futebolista. Capacidade de aceleração rápida, alta velocidade de corrida, boa habilidade para saltar, força explosiva dos músculos de membros inferiores, resistência de velocidade são exigidas constantemente dos atletas.

Considerado como uma modalidade esportiva acíclica, o futebol é composto de funções intermitentes em uma ação integrada, ou seja, o futebolista realiza durante a partida constantes movimentos defensivos e ofensivos.

Com relação ao sistema metabólico primário utilizado no futebol é importante lembrar que qualquer tipo de contração muscular só pode ocorrer na presença de adenosina 
trifosfato (ATP). O ATP é desdobrado em adenosina difosfato (ADP) e fosfato inorgânico (Pi) fazendo com que o músculo se contraia. Contudo, apenas uma pequena quantidade de ATP fica armazenada dentro do músculo, não sendo suficiente para cobrir a demanda energética realizada durante exercícios de alta intensidade, necessitando a cobertura da $\mathrm{CP}$, pois sua reserva é maior. Após a utilização da CP a compensação metabólica deve ser proveniente da glicólise anaeróbia e do sistema aeróbio, respectivamente.

Essa constatação fisiológica é de grande importância prática, pois, durante uma partida de futebol, a utilização e ressíntese rápida do ATP via $\mathrm{CP}$ e posteriormente pela glicólise anaeróbia torna-se o fator mais importante para fornecer energia ao esforço intenso do futebolista.

Observou-se que a CP é ressintetizada rapidamente após realização de um exercício intenso. Contudo, o período de tempo de recuperação durante uma partida de futebol em relação ao esforço de deslocamento e a pausa realizada pelo futebolista é muito curto. A CP como um sistema de compensação rápida de produção de energia muscular para exercícios realizados em alta intensidade não tem condições de compensar adequadamente o volume de energia necessário que ocorre nesse pequeno espaço de tempo e, assim, faz com que o futebolista, em diversos momentos da partida, solicite a via metabólica lática para dar continuidade ao esforço. Esses dois sistemas metabólicos são as fontes energéticas primárias de suporte específico para a prática do futebol.

Em 1995, Takahashi et al. ${ }^{3}$ demonstraram que o tempo requerido para a reposição intramuscular dos estoques de CP em músculos quadríceps de indivíduos não treinados pode variar de 55 a 90s. Contudo, não podemos esquecer que a eficiência metabólica da via alática no atleta é aumentada pelo treinamento. Atualmente os jogadores se movimentam em alta velocidade e, dependendo da posição do atleta, quase não há períodos de recuperação. Essas evidências mostram que os sistemas energéticos da CP e ácido lático devem ser considerados enfaticamente como mecanismo de compensação primária em relação às necessidades específicas do jogo.

O futebolista moderno cada vez mais realiza atividade motora prolongada e intermitente de alta intensidade. A preferência dominante pelos exercícios fracionados, com ou sem bola, deve ser enfocada como modelo estratégico utilizado no desenvolvimento dos sistemas energéticos solicitados pelo futebol. Essa constitui uma tendência mais moderna de orientação no treinamento do futebolista.

Outro fator que pode melhorar a performance em jogadores de futebol é o desenvolvimento de sua capacidade aeróbia. O treinamento aeróbio tem demonstrado aumentar a capacidade do músculo para extrair oxigênio, o que é considerado o fator primário no aumento da densidade capilar e secundariamente na concentração de mioglobina e mitocôndrias. Conseqüentemente o organismo desenvolve uma melhor habilidade para utilizar o oxigênio periférico durante trabalho muscular, determinando uma menor depleção de $\mathrm{CP}$ e acúmulo de lactato ${ }^{4,5}$.

A utilização dos sistemas anaeróbios alático e lático, como meio de compensar as necessidades específicas do jogo, deve ser desenvolvida com mais ênfase em sua fase competitiva. Ao contrário, o sistema aeróbio deve ser desenvolvido preferencialmente na fase pré-competitiva para aumentar a capacidade cardiorrespiratória. Durante a temporada competitiva devem ser desenvolvidos apenas trabalhos para a manutenção da curva fisiológica do metabolismo aeróbio.

Para vários clubes do futebol brasileiro o tempo disponível para preparação de seus jogadores é muito curto. Portanto, é de fundamental importância avaliar previamente os atletas com objetivo de verificar aqueles que precisam ou não de uma base aeróbia maior. Isso dará ao fisicultor informações que possibilitarão desenvolver o programa de treinamento de acordo com as necessidades individuais do atleta.

A verificação prévia do nível de aptidão física trouxe um posicionamento objetivo na preparação do atleta. Nesse aspecto os testes fisiológicos ganharam prestígio e tornaram-se importantes instrumentos dentro do planejamento inicial de treinamento do futebolista. Recentemente uma metodologia que conquistou o seu espaço foi a ergoespirometria computadorizada ${ }^{6-8}$, que, por meio da análise de gases expirados, possibilita verificar funções pulmonares ao esforço (fig. 1). Com esse método podemos quantificar parâmetros funcionais importantes como o consumo de oxigênio $\left(\dot{\mathrm{V}}_{2}\right)$, o limiar anaeróbio (ponto de transição metabólica), a cinética de oxigênio, etc. Além disso, os resultados verificados nos permitem avaliar, controlar e ajustar a carga individualizada de treinamento ao longo da temporada desportiva.

\section{1) Trabalho em equipe:}

a) O trabalho em equipe é de fundamental importância quando se trabalha com um grupo de profissionais especializados em busca de um objetivo. O fisiologista desportivo tem autonomia na programação e avaliação fisiológica dos atletas, sendo o único responsável pela tomada de decisão nessa área. Contudo, cabe a ele partilhar junto à comissão técnica, por meio de um diálogo franco, aberto e constante, sobre o perfil funcional dos atletas;

b) Cabe ao fisiologista desportivo atender às atribuições previamente definidas pela comissão técnica; 


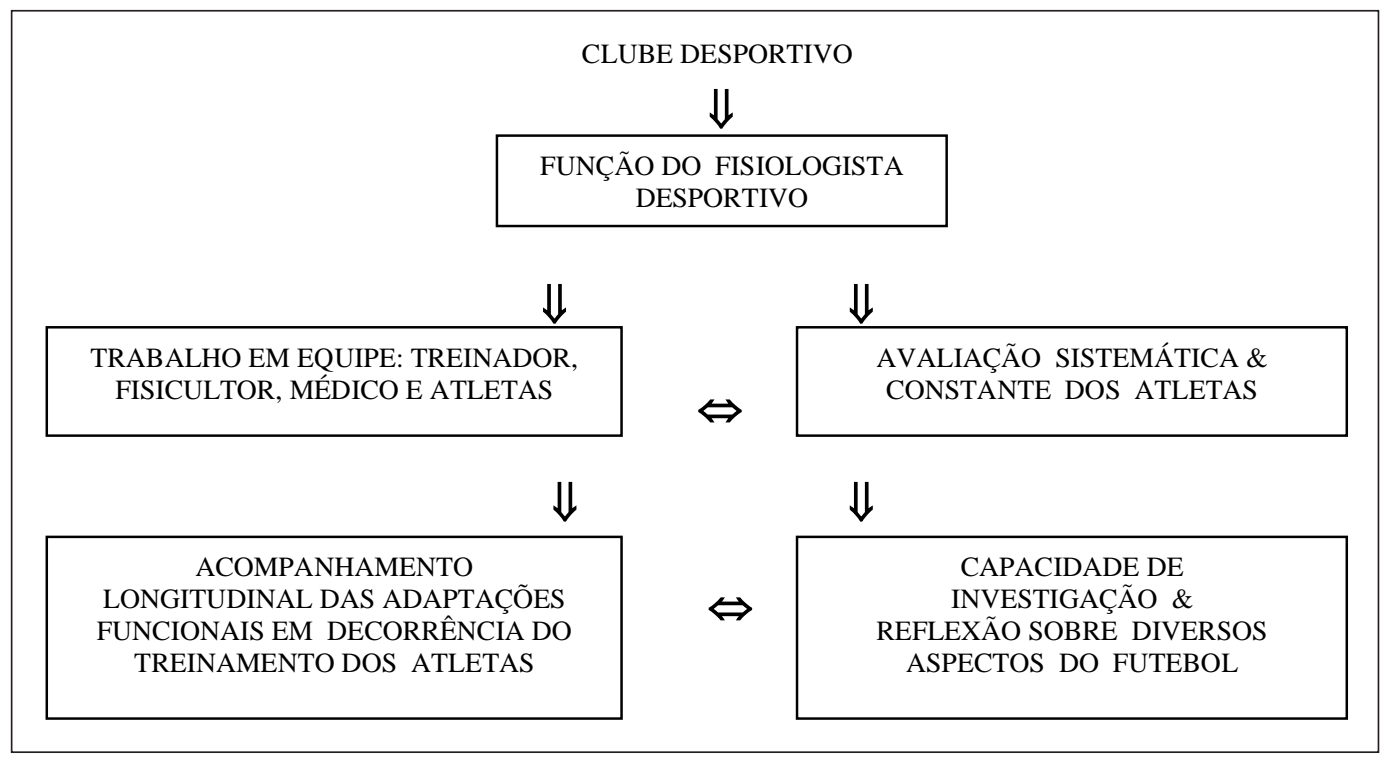

Fig. 1 - Organograma de atuação do fisiologista desportivo num clube de futebol

c) Planejamento integrado e participante das atividades e objetivos traçados pela comissão técnica;

d) Avaliação crítica dos resultados atingidos pelos atletas com reflexão sobre possíveis erros cometidos;

\section{2) Avaliação sistemática e constante dos atletas:}

a) O fisiologista desportivo deve avaliar de modo permanente o nível funcional de condicionamento atlético e os procedimentos utilizados pela comissão técnica às necessidades dos atletas.

\section{3) Acompanhamento longitudinal das adaptações fun- cionais em decorrência do treinamento dos atletas:}

a) Quando falamos de acompanhamento a longo prazo, ele só será possível nas situações em que o fisiologista desportivo se fizer presente em todos os momentos da atividade desportiva (avaliação, treinamentos e jogos).

\section{4) Capacidade de investigação e reflexão sobre diversos aspectos do futebol:}

a) Investigar e refletir sobre a prática diária dos treinamentos fundamentados em metodologias científicas;

b) Reconhecer limites e limitações pessoais;

c) Deve possuir traços de personalidade dirigida à pesquisa científica.

\section{A relação entre o técnico e o fisiologista desportivo no futebol}

A participação do fisiologista como membro da comissão técnica é relativamente nova. Porém, o trabalho em conjunto faz-se necessário, pois o técnico, na qualidade de coordenador da sua comissão, tem um papel fundamental na identificação e levantamento das necessidades dos seus atletas.

Infelizmente, não é louvável a posição das federações junto aos clubes de futebol, uma vez que essas não estimulam a participação desses especialistas em suas equipes.

O fisiologista desportivo é um profissional com formação específica, com capacidade para contribuir na melhora da prática desportiva, pois o objetivo final é o bem-estar dos jogadores.

\section{A relação entre o fisicultor e o fisiologista desportivo no futebol}

A preparação física direcionada a jogadores de futebol modificou-se com decorrer do tempo, estabelecendo novos conceitos e, até mesmo, exigindo uma participação maior do atleta em campo. Para enfrentar a magnitude dessa transformação, os clubes mais estruturados investiram em seus departamentos de futebol, contando com o apoio de diversos especialistas e com um maior investimento tecnológico.

Essa nova realidade trouxe ao futebol uma necessidade de desenvolver a área científica. Nesse contexto, a presença do fisiologista desportivo junto ao fisicultor ganhou um maior destaque. No passado os fisicultores não tinham ao seu lado a ciência do treinamento desportivo, se fazendo valer somente do conhecimento prático.

$\mathrm{Na}$ atualidade a metodologia científica com sua precisão predomina no treinamento físico do atleta. Verificou- 
se que o treinamento individualizado trouxe qualidade à preparação atlética e conseqüentemente um maior benefício aos jogadores.

O fisiologista, assim como o fisicultor, deve ter profundos conhecimentos na área de estratégia e organização do treinamento desportivo, pois somente assim será possível, dentro de um plano sistemático e individualizado, desenvolver corretamente o programa de treinamento.

\section{CONCLUSÃO}

Através desse artigo procuramos mostrar a importância do fisiologista desportivo como membro efetivo de uma comissão técnica. Entendemos que esse profissional ocupa um cargo relativamente novo no futebol, relacionandose diretamente com o fisicultor, aplicando e controlando metodologias científicas de avaliação e prescrição de treinamento aos jogadores de futebol.

\section{REFERÊNCIAS}

1. Silva PRS, Romano A, Visconti AM, Roldan A, Teixeira AAA, Seman AP, et al. Avaliação funcional multivariada em jogadores de futebol profissional: uma metanálise. Rev Bras Med Esporte 1998;4:182-96.

2. Raven PB, Gettman LR, Pollock ML. A physiological evaluation of professional soccer players. Br J Sports Med 1976;10:209-16.

3. Takahashi H, Inaki M, Fujimoto K. Control of the rate of phosphocreatine resynthesis after exercise in trained and untrained human quadriceps muscles. Eur J Appl Physiol 1995;71:396-404.

4. Jansson E, Dudley GA, Norman B, Tesch PA. Relationship of recovery from intense exercise to the oxidative potential of skeletal muscle. Acta Physiol Scand 1990;139:147-52.
De acordo com a interpretação dos testes realizados se farão programas individuais de treinamento, tornando esse trabalho de grande responsabilidade. O fisiologista tem a função de prever, com base num conjunto de resultados, de conhecimentos teóricos e fatores limitantes do rendimento, a evolução funcional dos atletas de acordo com o tempo disponível e o tipo de treinamento mais adequado para se atingir o nível ideal de condicionamento atlético dos jogadores.

Portanto, a performance desportiva ou o rendimento de alto nível está na dependência de um trabalho de equipe multidisciplinar.

\section{AGRADECIMENTOS}

Agradecemos à Dra. Fabiana Roveda, do Instituto do Coração do HCFMUSP, pela colaboração na redação deste artigo e ao Prof. Humberto Blancato pela tradução do abstract.

5. Donovan CM, Pagliassotti MJ. Enhance efficiency of lactate removal after endurance training. J Appl Physiol 1990;68:1053-8.

6. Hollmann W, Prinz JP. Ergospirometry and its history. Sports Med 1997; 23:93-105.

7. Yazbek Jr P, Camargo Jr PA, Kedor HH, Saraiva JF, Serro-Azul LG. Aspectos propedêuticos no uso da ergoespirometria. Arq Bras Cardiol 1985; 44:291-5.

8. Silva PRS, Romano A, Yazbek Jr P, Battistella LR. Ergoespirometria computadorizada ou calorimetria indireta: um método não invasivo de crescente valorização cardiorrespiratória ao exercício. Rev Bras Med Esporte 1998;4:147-58. 